\title{
On the use of telemedicine in the context of COVID-19: legal aspects and a systematic review of technology
}

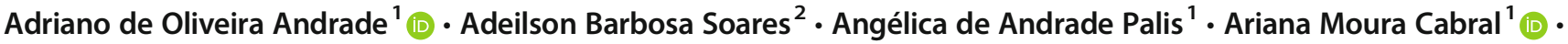 \\ Cassiana Gabriela Lima Barreto ${ }^{1}$ (D) - Daniel Baldoino de Souza ${ }^{1}$ (D) Fernanda de Paula Silva ${ }^{1}$ (D) \\ Fernando Pasquini Santos ${ }^{1}$ (D) - Gabriella Lelis Silva ${ }^{1}$ (D) - José Flávio Viana Guimarães ${ }^{1}$ (D) \\ Laureane Almeida Santiago de Araújo ${ }^{1}$ (D) - Lígia Reis Nóbrega ${ }^{1}$ (D) - Luanne Cardoso Mendes ${ }^{1}$ (D) \\ Luiza Maire David Luiz ${ }^{1}$ (D) - Mariana Ribeiro Brandão ${ }^{3}$ (D) - Selma Terezinha Milagre ${ }^{1}$ (D)

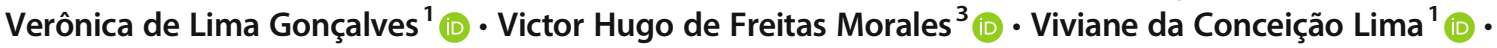 \\ Adriano Alves Pereira ${ }^{1}$ (D)
}

Received: 8 July 2020 / Accepted: 8 March 2021 / Published online: 13 March 2021

(C) Sociedade Brasileira de Engenharia Biomedica 2021

\begin{abstract}
Purpose The aim of this study was to carry out a systematic review of telemedicine technology and to discuss the role of legislation in the application of telemedicine technology within the scope of COVID-19.

Methods The search for papers was conducted in the databases Cochrane Central, MEDLINE, and Embase. The keywords considered for this systematic review were (coronavirus OR "2019-nCoV" OR 2019nCoV OR nCoV2019 OR "nCoV-2019" OR “COVID-19” OR COVID19 OR "HCoV-19” OR HCoV19 OR CoV OR "2019 novel*” OR Ncov OR "n-cov" OR "SARSCoV-2" OR "SARSCoV-2" OR "SARSCoV2" OR "SARSCoV2" OR SARSCov19 OR "SARS-Cov19” OR "SARS-Cov-19” OR “severe acute respiratory syndrome*” OR ((corona* OR corono*) AND (virus* OR viral* OR virinae*))) AND ((telemedicine OR telehealth OR "remote assessment" OR telemonitoring)). The review process was carried out by six independent reviewers, using the PRISMA-P method.

Results As a result, a total of 34 papers were selected, which addressed the study of telemedicine technologies used in times of endemics, epidemics, and pandemics, focusing on COVID-19.

Conclusion Telemedicine allows for care in remote areas and at a lower cost to the patient and, in the current situation, it can reduce the number of contagions as well as the occupation of beds in health facilities. Telemedicine may suffer from limitations, mainly due to current legislation, but in this pandemic era of COVID-19, several countries around the world have made their laws more flexible to allow more widespread use of telemedicine.
\end{abstract}

Keywords Pandemic $\cdot$ COVID-19 $\cdot$ Law $\cdot$ Technology $\cdot$ Telemedicine

Adriano Alves Pereira aalvespereira664@gmail.com

1 Centre for Innovation and Technology Assessment in Health, Faculty of Electrical Engineering, Federal University of Uberlândia, Uberlândia, Brazil

2 Faculty of Accounting Sciences, Federal University of Uberlândia, Uberlândia, Brazil

3 Institute of Biomedical Engineering, Federal University of Santa Catarina, Florianopolis, Brazil

\section{Introduction}

Telemedicine is defined by the World Health Organization (WHO) as the provision of health services at a distance, using electronic means for "diagnosis of treatment and prevention of diseases and injuries, research and evaluation, education of health professionals" (Serper and Volk 2018), being one of the main trends in the development of the modern health system for the diagnosis, treatment, and prevention of diseases.

The concept of telemedicine was introduced in the United States in 1993 as Medical Subject Headings and, in Brazil, in 1997. Since then, many changes have occurred in the laws and practice of Telemedicine. In Brazil, Resolution 1643/2002, of 
the Federal Council of Medicine (CFM), defined the application of telemedicine in healthcare, education, and research, requiring an appropriate technological infrastructure with confidentiality, privacy, and guarantee of professional secrecy of services provided (BRASIL 2002). However, the CFM did not specify the gold standard of the applicable technologies nor the legal framework to support the safe practice of this investigative process in health, in relation to the patient, or the medical professional.

According to Goodini et al. (2015), the main benefit of telemedicine is the ability to reduce or eliminate geographical distance (Neville 2018). In the scope of technologies used in telemedicine, although telephone and fax are still used, there is an increase in the use of the latest digital technologies (Roine et al. 2001). Thus, thanks to the growth of high-speed telecommunications networks and the ability to transmit highquality images and other clinical information, telemedicine has the potential to reduce costs and travel time for patients (Ellimoottil et al. 2016; Hersh et al. 2002).

Despite technological advances that promote the increase in telemedicine coverage, in order to be incorporated, just like any new technology, it must be more effective or more economical than the approach that it intends to replace (Roine et al. 2001). In this sense, the published evidence with better results on the effectiveness of telemedicine deals with teleradiology, teleneurosurgery, telepsychiatry, transmission of echocardiographic images, electrocardiograms, and teledermatology (Roine et al. 2001). There is also evidence that the history and physical examinations performed by telemedicine produce good sensitivity and specificity, especially in the areas of general practice and cardiology. However, in areas where patient abnormalities are more subtle, such as rheumatology and ophthalmology for glaucoma screening, telemedicine is still not as effective (Hersh et al. 2002).

Telemedicine is not limited to contexts between doctors and patients. The definition of telemedicine includes access to reliable websites that provide information on diseases, treatments, pharmaceuticals, and images of pathologies (Oudshoorn 2008). In this context, it is known as e-health (Breen and Matusitz 2010; Matusitz and Breen 2008).

For all the factors mentioned, there is currently a great enthusiasm for the use of telemedicine, but there are still several barriers to widespread its use (Ellimoottil et al. 2016; Kahn 2015). One of the first barriers is the health professional, because it is a big challenge for these professionals to adapt to the innovations of technologies and integrate these solutions into the flow of clinical work (Tuckson et al. 2017). While this limitation is exclusive to the health professional, other limitations are out of their control, such as the safety of patient data, location, and number of servers and lack of human resources to use, create, and maintain these tools (Breen and Matusitz 2010; Mort et al. 2003). However, one of the main limitations of the use of telemedicine is legislation (Dickens and Cook
2006). The legal and regulatory aspects of telemedicine involve licensing, accreditation, liability for medical negligence, and payment for services (Gupta and Sao 2011; Lilly et al. 2014; Spradley 2011).

The limitation due to the laws to apply telemedicine is more evident in pandemic situations when the response must be quick for society, and legal and regulatory challenges prevent immediate action. The current situation illustrates these legal and regulatory challenges well, as efforts to contain the COVID-19 pandemic include social detachment, quarantine, and isolation (Wright and Caudill 2020). Telemedicine works in these efforts through electronic and remote systems, which minimize the contact of health professionals with infected patients or those suspected of being infected (Grange et al. 2020). Telecommunication applications for health information, virtual consultations, appointment scheduling, verification of the patient's clinical history, access to laboratory results, and virtual platforms have been used by health professionals (Hollander and Carr 2020). Thus, the COVID-19 pandemic requires a reorganization of the infrastructure, processes, and priorities of the health system to assist individuals with suspected disease. Telemedicine has become a fundamental clinical process to face challenges in the control of pandemics by health systems, promoting good health practices, individually and in the community (WHO 2010). However, these actions using telemedicine were only possible thanks to a movement to make national and international standards and regulations more flexible, given the global health emergency circumstance, in order to better apply the fundamentals of medical call center remotely (Rockwell and Gilroy 2020).

In this sense, in Brazil, the Ministry of Health issued Ordinance No. 467, on March 20th, 2020, providing, "on an exceptional and temporary basis" of actions in Telemedicine, with the objective of regulating and operationalizing the measures to deal with the emergency of public health of international importance provided for in Art. 3 of Law No. 13,979, on February 6, 2020, due to the pandemic of COVID-19. Law no. 13,989, of April 15, 2020, was also enacted, which provides for the use of telemedicine during the pandemic situation caused by COVID-19 (BRASIL 2020b).

Telemedicine is known to be a promising tool for promoting health in isolated and rural communities and provides cost savings for both the patient and the healthcare system (private or public). In situations of health emergencies, such as a pandemic, it is necessary to use telemedicine to combat and mitigate the transmission of an infectious disease. On the other hand, the main disadvantages of using telemedicine are issues about confidentiality, information security, data protection, and patient treatment. In this context, the objective of this article was to conduct a literature review, focusing on concepts, applications, contributions, and laws related to the use of Telemedicine, at the global and national levels, notably in this SARS-CoV-2 pandemic situation. 


\section{Methods}

This systematic review was developed according to the Preferred Reporting Items for Systematic Reviews and Meta-Analysis (PRISMA-P) method (Moher et al. 2016).

\section{Study design}

Systematic review of prospective and retrospective studies follows the guidelines of PRISMA-P. The entire study selection process was carried out by six reviewers and summarized in a PRISMA flow diagram (Fig. 1). The authors searched articles that could answer questions relating to the use or proposals for the use of telemedicine within the scope of COVID-19. In addition, articles which dealt with legal aspects related to telemedicine were searched in a general and specific manner in relation to COVID-19. It is emphasized that legal aspects protect citizens, but if misused or misinterpreted, they may restrict the use of telemedicine. The Mendeley tool was used to manage references.

\section{Inclusion/exclusion criteria}

Eligible articles accounted for studies with telemedicine focused on COVID-19. Due to the lack of randomized controlled trials, the authors also included epidemiological studies, cross-sectional studies, case studies, clinical observations, health organ reports, prospective cohort, case-control studies, systematic reviews, meta-analyses, and non-randomized studies associated with COVID-19. The research covered Portuguese and English languages and was limited to articles published in 2020. A bibliographic review was conducted between March and November 2020.

\section{Search sources}

In order to define the terms of the search, an investigation was carried out in the previous systematic reviews on the subject to identify the relevant terms.

Three databases were consulted as suggested by (Singh et al. 2020): Cochrane Central, MEDLINE, and Embase. Also, the gray literature was consulted, mainly on government
Fig. 1 Flowchart of the search process

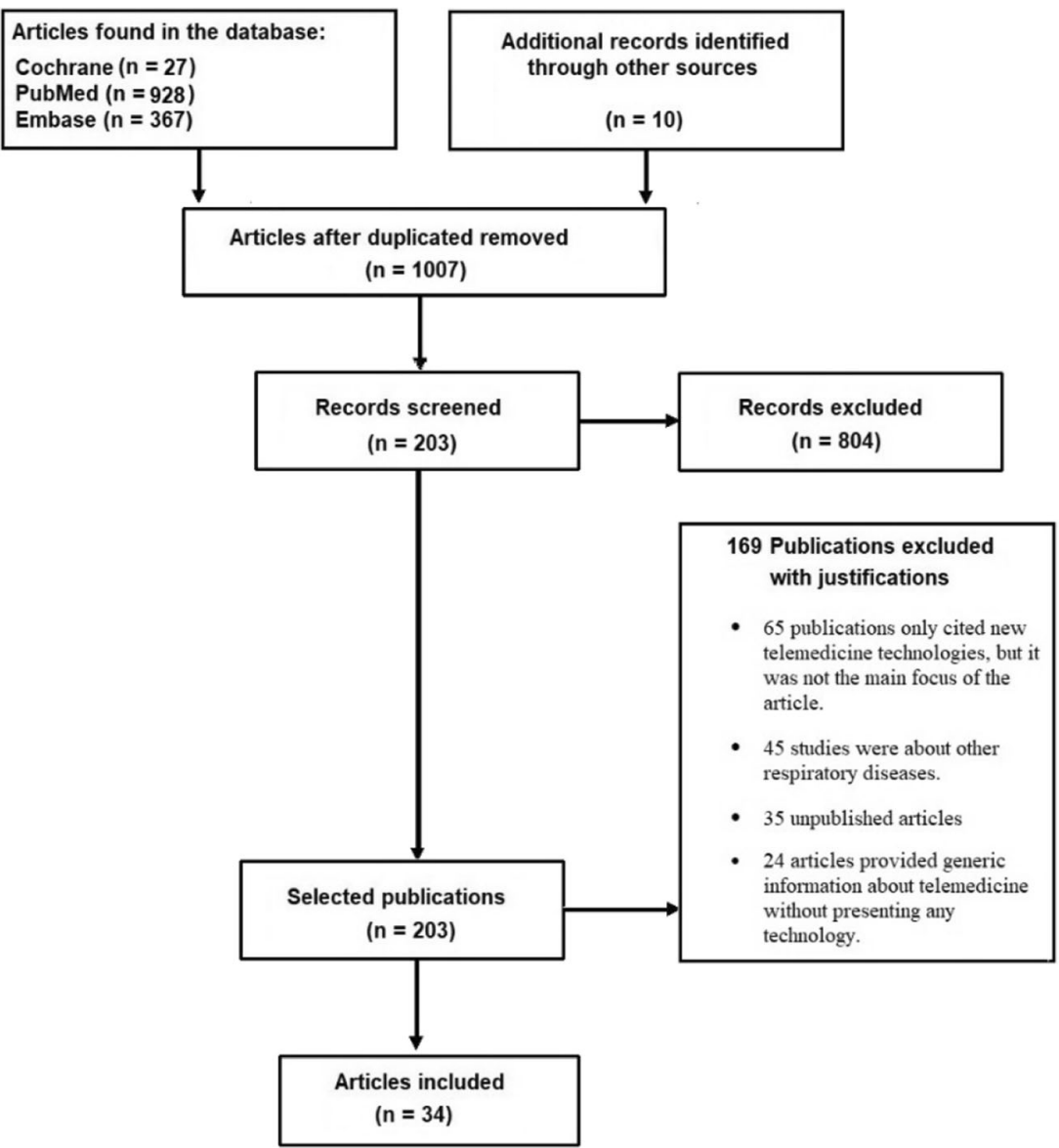


websites, by using the search terms and strategy described below (Singh et al. 2020):

\begin{tabular}{|c|c|}
\hline $\begin{array}{l}\text { Cochrane } \\
\text { Central }\end{array}$ & 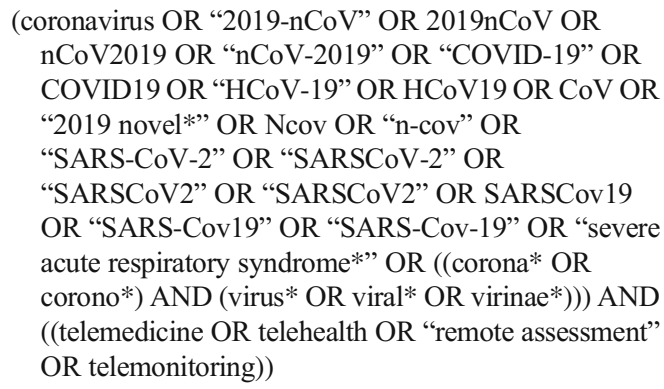 \\
\hline MEDLINE & 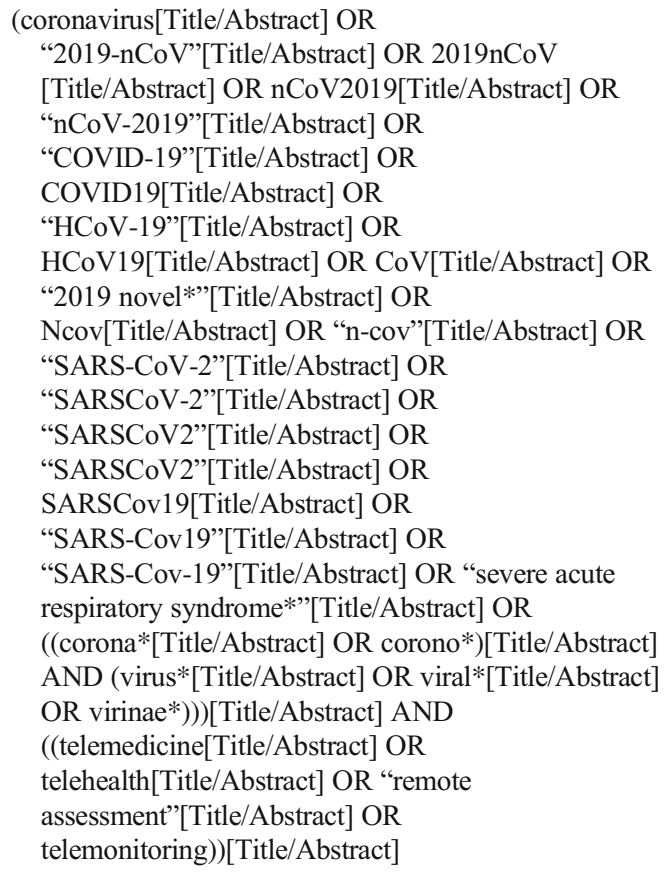 \\
\hline Embase & $\begin{array}{l}\text { (coronavirus:ab OR ‘2019-ncov':ab OR 2019ncov:ab OR } \\
\text { ncov2019:ab OR 'ncov-2019':ab OR ‘covid-19':ab } \\
\text { OR covid19:ab OR 'hcov-19':ab OR hcov19:ab OR } \\
\text { cov:ab OR '2019 novel*':ab OR ncov:ab OR } \\
\text { 'n-cov':ab OR 'sars-cov-2':ab OR ‘sarscov-2’:ab OR } \\
\text { 'sarscov2':ab OR sarscov19:ab OR ‘sars-cov19':ab } \\
\text { OR ‘sars-cov-19':ab OR ‘severe acute respiratory } \\
\text { syndrome*':ab OR ((corona*:ab OR corono*:ab) } \\
\text { AND (virus*:ab OR viral*:ab OR virinae*:ab))) AND } \\
\text { (telemedicine:ab,ti OR telehealth:ab,ti OR 'remote } \\
\text { assessment':ab,ti OR telemonitoring:ab,ti) AND } \\
\text { [embase]/lim AND [article]/lim AND 'human'/de } \\
\text { AND 'article'/it AND [embase]/lim }\end{array}$ \\
\hline
\end{tabular}

\section{Telemedicine technologies included}

Our criteria of inclusion of telemedicine technologies were unrestricted, however, specific to treatments on COVID-19.

\section{Selection}

Four authors independently analyzed the titles and abstracts of the studies identified by the research strategy and checked the existing duplicates to remove them. Eligible studies are reassessed by reading the full text to compose this systematic review. In case of disagreement on the chosen articles, the opinion of a fifth author would be requested. However, this was not necessary. The flowchart in Fig. 1 shows the study selection process.

\section{Data collection}

Two authors extracted data from the selected articles and two other authors verified the accuracy and fidelity of the data presented and another author resolved the existing disagreements. However, no study required consultation with a fifth reviewer.

\section{Assessment of bias quality and risk of included studies}

The methodological quality of the included primary studies has not been carried out, given the recent and abrupt impact of this health emergency on public health services globally. However, the search for articles was carried out only in reliable databases with recognized quality, and the following items were analyzed:

- All articles that presented treatment with medications, but COVID-19 was not the main focus of the study, were excluded.

- All articles that caused doubts about the inclusion in this systematic review were evaluated again for relevance.

- Studies with failure to follow-up above $10 \%$ were excluded.

\section{Results}

The search in the databases resulted in a total of 1332 studies that had in their titles, or in the keywords, and the search terms. The duplicates were disregarded, and 1007 articles remained. After analyzing the titles and abstracts, 203 articles were selected.

The reading of these 203 articles full text resulted in 169 articles excluded, in which 65 publications only cited new telemedicine technologies, but it was not the main focus of the article, 45 studies were about other respiratory diseases, 35 unpublished articles, and 24 articles provided generic information about telemedicine without presenting any technology.

Thus, 34 articles were eligible to compose this systematic review, which present laws and technologies that are or have been used in several countries to combat endemics, epidemics, and pandemics of respiratory diseases, mainly related to COVID-19. 
The studies were grouped according to the methods used, as shown in Table 1.

\section{Discussion}

For the discussion of the legal aspects and the systematic review carried out on the Telemedicine technologies currently used in the scope of COVID-19, it is important to check the evidence on the use and importance of telemedicine in combating COVID-19.

\section{Evidence of the use of telemedicine to combat COVID-19}

Ohannessian et al. (2020) used a literature review on the use of telemedicine in other pandemics, to define an update to be used in the treatment of COVID-19. The objective of telemedicine implemented in France against COVID-19 was to avoid agglomerations, track, and detect possible cases of the new coronavirus and monitor patients with mild symptoms of the disease.

Portnoy et al. (2020) conducted searches on studies that prove the efficacy of the use of telemedicine. In this research, the authors affirm that telemedicine is a safe and effective alternative to care for patients confirmed with COVID-19 who present mild symptoms of the disease, thus avoiding the spread of the virus to other patients who need the faceto-face health service and health professionals. The authors conclude that telemedicine has been more used in this pandemic; however, some barriers were observed: given the need, patients tend to return to use means of face-to-face care, also patients prefer care from those who have already had a previously established relationship, and, finally, the lack of information about the option of using telemedicine and how to access it. Given this situation, the main role now is to show the efficacy and safety of the use of telemedicine in circumstances such as coping with COVID-19, expansion of physicians who attend remotely, help to understand how telemedicine works and how access should be, and cost reduction to access telemedicine (Portnoy et al. 2020).

According to Portnoy et al. (2020), the evaluation of the patient using telemedicine includes observing the physical appearance of the patient, measuring the temperature with a domestic thermometer (performed by the patient himself), calculating respiratory rate and observing breathing (checking, for example, if the patient is panting), verifying the presence of cough, among other measures. After this evaluation, the physician will determine the need for testing for COVID-19. Finally, the authors reported a systematic review by Cochrane in 2015 on the use of telehealth compared to face-to-face care in health services in patients with chronic conditions, such as diabetes, and heart failure. As a result, they found similarities in both cases (Portnoy et al. 2020).

Smith et al. (2020) describe the requirements for the use of telemedicine, both in emergency cases such as the COVID-19 pandemic and in daily practice. The study listed the main barriers faced to the use of telemedicine, such as low adherence, lack of funding, and the need to reorganize the health system. These factors are pointed out as possible causes of the low use of remote attention.

Hong et al. (2020) investigated the volume of internet research on telemedicine in the USA, using Google Trends, in the period of January 21 (first report of the new coronavirus in the USA) to March 18, 2020; the number of new cases of COVID19 was obtained from the Johns Hopkins Coronavirus Resources Center; data of 2018 from AHAAS were used to estimate the proportion of hospitals that adopted telehealth. The authors reported that there was an increase in the interest of the American population as the number of COVID-19 cases increased. In the survey, it was found that there was a greater proportion of hospitals that adopted telemedicine in the centerwest of the country. However, it was observed that the population of the northeast and west regions had a greater interest in telehealth. There was no significant association between the population's interest and the proportion of hospitals that adopted telehealth.

Sun et al. (2020) wrote a letter reporting the importance of using online services in the COVID-19 era. As a way to combat the new coronavirus, China encouraged the treatment model via remote care as a way to avoid crossinfection and minimize the burden on health services. Telemedicine care has advantages, such as greater efficiency at low cost and treatment without contact with the patient. In addition to remote care in cases of COVID-19, China made telemedicine available to patients with other diseases, increasing the use of telemedicine by $278 \%$ from January 22nd to February 25th compared to the previous month. Because of the situation, the "internet hospitals" in China have obtained satisfactory results; this is since the Chinese government has issued a series of policies to integrate the use of online medical services. Also, innovative technologies such as artificial intelligence, $5 \mathrm{G}$, and big data have been applied (Sun et al. 2020).

Turer et al. (2020) discussed safety, legal, and technical factors needed to implement the use of telemedicine. The authors recommend the use of telemedicine to protect health professionals and conserve their protection equipment, providing quick access to emergencies, maintaining safety standards for emergency medical screening tests in patients with low suspected risk of COVID-19, and meeting Emergency Medical Treatment and Active Labor Act obligations during the COVID-19 pandemic.

Moazzami et al. (2020) wrote a letter of recommendation on the importance of using telemedicine in coping with 
Table 1 Included studies on technologies in telemedicine used in the context of COVID-19

Authors Technology

Description

Berg et al. (2020)

(BRASIL 2020a)

Calton et al. (2020)

Connor et al. (2020)

Dashraath et al. (2020)

Davarpanah et al. (2020)

FRANCE (2020)

Ghosh et al. (2020)

Grange et al. (2020)

Hollander and Carr (2020)

(Hong et al. 2020)

Huang et al. (2020)

Jakhar et al. (2020)

Lakkireddy et al. (2020)

Li et al. (2020)

Moazzami et al. (2020)

Myers et al. (2020)

Ohannessian et al. (2020)

Perez-Alba et al. (2020)

Portnoy et al. (2020)

Posenato (2020)

Rogers et al. (2020)

Rubin et al. (2020)

Shanthanna et al. (2020)

Smith et al. (2020)

Sun et al. (2020)

Taheri et al. (2020)
Medicare Telehealth Visits, Medicare Virtual Check-in, Medicare e-Visit, Amwell for patients, Amwell Avizia, Epic: Mobile Haiku; e Mobile Canto, Zoom Video Communication: Zoom for Healthcare

It provides, on an exceptional and temporary basis, telemedicine actions, with the aim of regulating and operationalizing the measures to deal with the international public health emergency provided for in Art. 3 of Law No. 13,979, of February 6, 2020, due to the COVID-19 epidemic.

Apple FaceTime, Google Hangouts, Google Duo, Microsoft Skype, Cisco WebEx, Whatsapp, Facebook Messenger, Email providers. The authors reported tips to support the use of telemedicine in the face of the new coronavirus pandemic.

Attend Anywhere

Zoom Video Communication: Zoom for Healthcare, Apple FaceTime, Google Hangouts, Google Duo, Microsoft Skype, Cisco WebEx, WhatsApp, Facebook Messenger, Email providers.

Apple FaceTime, Google Hangouts, Google Duo, Microsoft Skype, Cisco WebEx, WhatsApp, Facebook Messenger, Email providers.

Adapts the conditions of the benefit of health insurance and coverage of telemedicine acts for people exposed to COVID-19

Apple FaceTime, Google Hangouts, Google Duo, Microsoft Skype, Cisco WebEx, WhatsApp, Facebook Messenger, e-mail providers.

Epic: Telehealth

Cleveland Clinic Express Care, Mount Sinai NOW, Kaiser Permanente Telehealth System, Teladoc Health, Mercy Virtual Care Center: MyChart, Mercy Virtual Care Center: SafeWatch, Sutter Health: My Health Online, Sutter Health: Electronic ICU, Sentara Healthcare: Sentara Mobile App, Sentara Healthcare: Sentara e-ICU, Aurora Health Care, Amwell for patients.

The authors investigated the volume of internet searches for telemedicine in the USA, using Google Trends, in the period January 21st (first report of the new coronavirus in the USA) on March 18, 2020; the number of new cases of COVID-19 was obtained from the Johns Hopkins Coronavirus Resources Center, and data from the 2018 American Hospital Association Annual Survey (AHAAS) were used to estimate the proportion of hospitals that adopted telehealth.

WeChat

Apple FaceTime, Google Hangouts, Google Duo, Microsoft Skype, Cisco WebEx, WhatsApp, Facebook Messenger, e-mail providers.

Medicare e-Visit, Apple FaceTime, Google Hangouts, Google Duo, Microsoft Skype, Cisco WebEx, WhatsApp, Facebook Messenger, e-mail providers.

WeChat

The authors wrote a letter of recommendation on the importance of using telemedicine in coping with COVID-19.

My HealtheVet, Apple FaceTime, Google Hangouts, Google Duo, Microsoft Skype, Cisco WebEx, WhatsApp, Facebook Messenger, e-mail providers.

The authors used a literature review on the use of telemedicine in other pandemics, in order to define and update it to include in the treatment of COVID-19.

Apple FaceTime, Google Hangouts, Google Duo, Microsoft Skype, Cisco WebEx, WhatsApp, Facebook Messenger, e-mail providers.

The authors conducted searches on telemedicine and studies that prove the effectiveness of its use.

Coronavirus SUS

Medicare Telehealth Visits, Medicare Virtual Check-in, Medicare e-Visit, Apple FaceTime, Google Hangouts, Google Duo, Microsoft Skype, Cisco WebEx, Whatsapp, Facebook Messenger, e-mail providers.

Apple: Apple Watch, AliveCor: KardiaMobile, Apple FaceTime, Google Hangouts, Google Duo, Microsoft Skype, Cisco WebEx, WhatsApp, Facebook Messenger, e-mail providers

Microsoft Teams

The authors described the requirements for the use of telemedicine, both in emergency cases such as the COVID-19 pandemic, and in daily practice.

The authors wrote a letter reporting the importance of using online services in the COVID-19 era.

Apple FaceTime, Google Hangouts, Google Duo, Microsoft Skype, Cisco WebEx, Whatsapp, Facebook Messenger, e-mail providers. 
Table 1 (continued)

\begin{tabular}{ll}
\hline Authors & $\begin{array}{l}\text { Technology } \\
\text { Description }\end{array}$ \\
\hline $\begin{array}{l}\text { Tran et al. (2020) } \\
\text { Turer et al. (2020) }\end{array}$ & $\begin{array}{l}\text { Medicare Telehealth Visits } \\
\text { inDoc: Teletriage, Apple FaceTime, Google Hangouts, Google Duo, Microsoft Skype, Cisco WebEx, Whatsapp, } \\
\text { Facebook Messenger, e-mail providers. The authors discussed safety, legal, and technical factors necessary to } \\
\text { implement the use of telemedicine. }\end{array}$ \\
$\begin{array}{l}\text { ANITED STATES OF } \\
\text { AMERICA (2020b) }\end{array}$ & $\begin{array}{l}\text { Telehealth Services during certain emergency periods. } \\
\text { Waters (2020) }\end{array}$ \\
$\begin{array}{l}\text { Fong et al. (2020) } \\
\text { Yang et al. (2020) }\end{array}$ & $\begin{array}{l}\text { Wearable biosensors to monitor physiological parameters for early detection of COVID-19 clinical progression. } \\
\text { Zhou et al. (2020) }\end{array}$ \\
\hline
\end{tabular}

COVID-19. In research conducted, the authors reported that the use of telemedicine was widely evaluated by several hospital systems, such as Jefferson Health, Cleveland Clinic, and the University of Pittsburgh, which provide online neurological assessments for patients with severe neurological problems. According to the authors (Moazzami et al. 2020), the decrease in health professionals due to the contagion COVID19 is a concern in the face of the pandemic. For them, the use of telemedicine should play an important role in reinforcing that these professionals, even if they are in quarantine, continue to assist patients with suspected disease remotely.

\section{Telemedicine and the laws}

In this context, it was necessary to conduct a research related to the practice of telemedicine from a legal point of view, which, for this study, included articles that discussed the topic and the laws and regulations of each country. In addition, research has been carried out regarding possible changes in the regulations for the practice of telemedicine in the face of the new coronavirus pandemic.

In order to ensure that the main barriers prevent the use of telemedicine, there was a need to establish laws and regulations around the world to ensure that remote healthcare practices are carried out in an ethical, confidential, and safe manner.

\section{Definitions}

In Brazil, Resolution 1643/2002 defined telemedicine as an exercise in medicine using interactive methodologies of audiovisual communication and data, with the objective of assistance, education, and research in health, while telehealth means how to provide health and public health services through information and communication technologies to facilitate the diagnosis, consultation, treatment, education, care management, and self-management of a patient's healthcare while he is at the place of origin and the health professional is in another location (Silva et al. 2015a). Additionally, Resolution 1643/2002 informs the need for appropriate technological infrastructure and confidentiality, privacy, and professional confidentiality of the services provided. Thus, the physician is authorized to issue remote reports and provide diagnostic and therapeutic support (BRASIL 2002).

In the United States of America (USA), the law project $A B$ 415 updated the legal definitions of telehealth, simplified medical approval processes for services provided by telehealth, and expanded the types of permitted services provided by telehealth. AB 415 replaced the term "telemedicine" with "telehealth."

In France, according to Article L6316-1, telemedicine is a form of remote medical practice using information and communication technologies, which brings together a patient, one or more health professionals, including necessarily a medical professional and, where appropriate, other professionals who provide care to the patient. The practice of telemedicine makes it possible to establish a diagnosis and ensure, for a patient at risk, follow-up with a preventive objective or post-therapeutic follow-up, demand a specialized opinion, prepare a therapeutic decision, prescribe products, and prescribe or perform services or acts or monitor the condition of patients (FRANCE 2019).

Federal Law No. 323-FZ in Russia discusses the basic protection of citizens' health. According to the law, telemedicine technology is defined as:

Information technologies that provide remote interaction of medical workers with each other, with patients and/or their legal representatives, identify and authenticate 
specified people and document their actions during consultations and remote medical care (Karyagina and Sitdikova 2019; Lindenbraten 2012).

In South Korea, telehealth legislation was introduced in 2003 and defined it as "the use of information technology by doctors to transmit medical technology and/or knowledge at a distance." Telehealth has not been actively deployed in health services, due to the lack of support infrastructure and the reluctance of primary care physicians. However, the Ministry of Health and Welfare proposed a revision of the telehealth legislation in 2009. The revised telehealth legislation allows for direct teleconsultation between patient-doctor, receipt of the prescription, and forwarding of electronic prescription to the pharmacy (Kim et al. 2011).

\section{Ethical questions}

Langarizadeh et al. (2017) conducted a literature search on ethical issues in telemedicine. As a result of the systematic review, the authors highlighted that the main ethical issues to be investigated are technology, telephone, internet, email, doctor-patient relationship, confidentiality and data security, informed consent, and patient satisfaction with telemedicine services.

For Mehta (2014), although there are numerous advantages of telemedicine practice, there are a number of concerns that must be addressed to ensure that telemedicine is ethically acceptable. For this, it is important to have a strong patientdoctor relationship. The American Medical Association emphasizes that telemedicine is a complement to personal care and only for those patients who already have a pre-existing relationship with the doctor. However, telemedicine appears as an opportunity to improve access to medical care in limited geographic areas (Mehta 2014).

In the state of California, USA, AB 415 requires a healthcare professional to obtain written and verbal informed consent from the patient or their legal guardian before telemedicine is used. In addition, it explicitly removed the limits of telehealth locations, allowing any type of telehealth, regardless of where it occurs, in addition to removing the ban on services by email or telephone, included all licensed health professionals in California as telehealth providers and has enabled California hospitals to optimize medical accreditation for telehealth providers (UNITED STATES OF AMERICA 2011).

Health Professions Council of South Africa (HPCSA) guidelines prohibit the use of apps, questionnaires, and consultations without a physician in South Africa, on the grounds that treatment based on a questionnaire alone is not considered an acceptable standard of care. For the practice of telemedicine, there must be informed consent from the patient to receive care (Ateriya et al. 2018; Barit 2019; SOUTH AFRICA 2019).

\section{Reimbursement}

In Washington, USA, RCW 74.09.325 deals with the reimbursement of a health service provided by telemedicine or storage and referral technology. A healthcare system must reimburse a provider for a healthcare service provided to a person covered by telemedicine whether the healthcare plan in which the covered person is enrolled provides healthcare coverage when provided in person; the health service is medically necessary; the health service is certified for safety and effectiveness through telemedicine or storage and referral technology in accordance with generally accepted health practices and standards; and the technology used to provide the health service meets the standards required by the state and federal regulations (UNITED STATES OF AMERICA 2017).

In the European Union (EU), Articles 56 and 57 of the Treaty on the Functioning of the European Union guarantee that telemedicine is a free service. According to Directive 2011/24/EU, the patient is entitled to receive medical treatment in another Member State (Article 1) and, under certain conditions, to be reimbursed; right to access medical records, in written or electronic format, containing all relevant information related to the treatment received; if requested, the patient also has the right to be informed about the quality and safety standards and guidelines existing in the Member State where the treatment is carried out or, in the case of telemedicine, where the doctor is based; and right to be informed about the availability, quality, and safety of the service used (Gioia and Salducci 2019; Raposo 2016).

The Telehealth Advancement Act, 2012, includes a greater number of telemedicine services and reimbursement processes. The Louisiana Telehealth Access Act and the Minnesota's Medicaid program allow patients to be reimbursed for their expenses. In Washington DC, there is a provision for reimbursement for telemedicine services under the Telemedicine Reimbursement Act 2013. The states of California and Louisiana have an "informed consent policy" for telemedicine (Ateriya et al. 2018).

According to Baumann et al. (2020), the reimbursement for telehealth can be much less than face-to-face consultations and this loss of revenue may make telehealthcare unfeasible for clinics and hospitals. On the other hand, due to the fear of suffering from COVID-19, the patient does not give priority to attending personal care with direct contact unless he/she is at an advanced stage of the disease (Baumann et al. 2020). Reimbursement may therefore be important to allow early diagnosis of the disease, to allow treatment even at an early stage, and to relieve intensive care unit (ICU). 


\section{Data safety}

For the HPCSA guidelines, a medical examination must be performed, with a survey of the patient's medical history and a physical examination. In addition, the healthcare professional remains responsible for the treatment, decisions, and other recommendations given to the patient, as well as maintaining details of the patient's condition records and information transmitted and received. Health professionals who practice telemedicine must provide safe procedures, ensure that patient information obtained electronically is maintained in accordance with the HPCSA guidelines, and avoid loss of patient information, patient information being transmitted encrypted (Ateriya et al. 2018; Barit 2019; SOUTH AFRICA 2019).

Calleja-Castillo and Gonzalez-Calderon (2018) discussed the use of WhatsApp as a clinical tool, addressing regulatory issues and concerns about data privacy. According to the authors, in the United Kingdom (UK), applications were developed as safe alternatives and compatible with the National Health Service (NHS), for communication and sharing of clinical experiences between teams and doctors in a local network or worldwide. Examples of applications used in the UK are medCrowd, Medicbleep, Hospify, and Forward. Although the use of apps developed for medical purposes in the UK, social networks, more specifically WhatsApp, have also been a choice between doctors and patients. However, NHS England's official advice is not to use WhatsApp to send health information (Calleja-Castillo and Gonzalez-Calderon 2018).

In Mexico, the regulatory authorities are the Ministry of Health (Secretariat of Health and Assistance) and the National Institute for Transparency, Information Access and Personal Data Protection, which issue the General Health Law and the Federal Transparency and Access to Public Government Information Law (LFTAIPG), respectively (Calleja-Castillo and Gonzalez-Calderon 2018). The General Board of Health Information published the standard NOM024-SSA3-2012 on legislation and electronic interaction between health professionals and establishes that all electronic communications must be established through an Electronic Health Record Information System that meets the requirements of the LFTAIPG. This law, however, is rarely applied (Calleja-Castillo and Gonzalez-Calderon 2018).

In the USA, legal considerations related to telemedicine fall into 6 distinct categories: medical licensing, professional liability, online prescription, informed consent (including data security), accreditation, and definition of the patient-doctor relationship. In addition, the professional service provider using telemedicine must confirm that providers who are affiliated have relevant privacy policies (Chaet et al. 2017; Emergency Medicine Telemedicine 2016).

According to Vokinger et al. (2020), the collection of digital data by digital devices is extremely sensitive, as the data is collected with a very wide use premise. In addition, the description of the applications does not provide sufficient information for the user to analyze the risk of violation of the data. The author cites Swiss legislation which promotes strict control over the protection of personal data. Under Swiss law, health data is assessed and required for additional protection of privacy in relation to other personal data, one of which is that each user must give his or her "informed consent" (Vokinger et al. 2020).

Bakibinga-Gaswaga et al. (2020) comment on infrastructure problems that exist in sub-Saharan Africa, but which can be generalized to low-income countries, one of which is the detection and management of transmission errors, which can compromise patient privacy during wireless transmission. In addition, in several countries, there are no personal data protection laws (Bakibinga-Gaswaga et al. 2020).

\section{Relaxation of laws due to COVID-19}

It is clear from the regulations of several countries that the main issue involving the practice of telemedicine is related to the protection of patient data. In addition, telemedicine needs secure digital resources that guarantee data privacy and confidentiality, and the care provided is the responsibility of the health professional. For the use of telemedicine, there is a need for a free and informed consent term, where the document must be informed to the patient about the data collection, the objectives of the treatment, who can have access to the data, identification details, and the methods to protect patient data.

There is no lack of alternatives for the application of more flexible laws, in some countries, there is an acceleration of the approval of laws, for example, in Israel, where a law to track cell phones of people with COVID-19 was approved, to identify and quarantine other people with whom they came into contact and may have become infected. The law passed an evening session bypassing parliamentary approval (Ekong et al. 2020; Tidy 2020).

In Brazil, Ordinance $\mathrm{N}_{-}^{0} 467$ of March 20, 2020, provides, on an exceptional and temporary basis, telemedicine actions, with the objective of regulating and operationalizing the measures to deal with the international public health emergency provided for in Article 3 of Law $\mathrm{N}_{-}^{0} 13,979$, of February 6, 2020, due to the epidemic of COVID-19. Article 2 of the ordinance reports that telemedicine actions of remote interaction can include pre-clinical care, assistance support, consultation, monitoring, and diagnosis, through information and communication technology, within the scope of the Brazilian Unified Health System (SUS), as well as in supplementary and private health. According to Art. 4, the care provided by a doctor to the patient through information and communication technology must be registered in a medical record, which must contain clinical data necessary for the good conduct of the case, being 
filled out in each contact with the patient; date, time, information, and communication technology used for the service; and number of the Regional Professional Council and its federation unit. According to Art. 5, doctors may, within the scope of telemedicine assistance, issue medical certificates or prescriptions in electronic media. The issuing of prescriptions and medical certificates at a distance will be valid electronically, using an electronic signature, through certificates and keys issued by the Brazilian Public Key Infrastructure - ICP-Brasil, in accordance with Art. 6 of the Ordinance (BRASIL 2020a).

In the USA, there have been legal and regulatory changes to facilitate the use of telemedicine, including expanding reimbursement for telemedicine services; relaxation of technology requirements; implementation of new licensing and accreditation approaches; and relaxation of supervisory laws related to non-medical service providers. In response to the COVID-19 outbreak, President Donald Trump signed the Complementary Coronavirus Appropriation and Response Act on March 6, 2020, which includes $\$ 8$ billion in emergency funding and allows Health and Human Services (HHS) to waive certain Medicare (USA government-managed health insurance system) requirements to expand reimbursement for telehealth services temporarily during the coronavirus public health emergency (Rockwell and Gilroy 2020; UNITED STATES OF AMERICA 2020b). The Coronavirus Aid, Relief, and Economic Security (CARES) Act was passed on March 27, 2020; the Congress passed CARES Act (HR748), the third package in response to the public health emergency of COVID-19. The CARES Law signals strong support for telehealth and the Congress' recognition that expanding access to virtual care is fundamental to defeating COVID-19 (Courtney 2020).

Many countries in the EU and Asia have expanded their laws and regulations as a way to allow more practice in the use of telemedicine, providing more guidance on cybersecurity technologies and expectations, as well as expanded reimbursement options. Italy does not include telemedicine in the essential levels of care provided to all citizens of the NHS, despite the high pressure on health services during the first phase of the COVID-19 epidemic. France has authorized, reimbursed, and actively promoted the use of telemedicine, as a way of avoiding crowding, tracking and detecting possible cases of the new coronavirus, and monitoring patients with mild symptoms of the disease. The decree was signed on March 9, 2020, allowing reimbursement of videoconference and teleconsultation by the National Health Insurance for patients with symptoms of COVID-19 and confirmed cases of the disease even without the need for a pre-existing doctorpatient relationship (FRANCE 2020; Ohannessian et al. 2020).

In Russia, telemedicine services were regulated only in 2018, with the entry into force of Federal Law No. 242, of July 29, 2017 ("Telemedicine Law"). The Telemedicine Law allowed doctors to provide various online services, such as consultations and patient follow-up. However, the exclusively online diagnosis was not allowed. Due to the rapid dissemination of COVID-19, there is an ongoing Law Project so that the diagnosis of patients can be carried out exclusively online (Gulyaeva et al. 2020).

\section{Telemedicine technologies used in healthcare}

Telemedicine technologies are increasingly integrated into health systems, especially infectious disease programs. Telemedicine practices aim to increase access to clinical medical care to isolated and rural populations, eliminating distance barriers with better conditions of access to medical services that would otherwise not be available. Telemedicine remotely links patients to specialized healthcare professionals at low costs, but with quality, in an attempt to increase access to health systems for all who need it.

In this context, according to the selected articles for this review, it was initially necessary to verify in which scenarios the implementation and adoption of telemedicine are necessary. It is known that telemedicine is a promising propaedeutic instrument for health promotion in isolated and rural communities and provides a reduction in expenses for both the patient and the health system (private or public). In situations of sanitary emergencies, such as a pandemic, it is necessary to use telemedicine to combat and mitigate the transmission of an infectious disease. Currently, the world is facing a pandemic caused by the new coronavirus SARS-CoV-2 and health systems around the world are not prepared to face and minimize the damage caused by COVID-19 (World Health Organization (WHO) 2020).

Many specifications of hardware and software systems, some known and usually globalized, have been used in telemedicine. The mHealth system was adopted in the USA, as a support tool for the Infectious Diseases Society of America and is used as telehealth and telemedicine systems technology with a focus on populations with limited resources. This system provides health services for mobile devices through synchronous telemedicine (by video call) between the patient and the clinician and asynchronous (patient information is sent to the health professional and the health professional responds when he/she can). This type of system supports potential cost savings, reduces system-wide spending, and enables real-time communication and remote monitoring of patients in emergency departments or patients who are in isolated or hard-to-reach locations, e.g., prisons, rest clinics, and rural communities (Young et al. 2019). Additionally, the USA has adopted the tele-SUD, which is an apparatus that works through synchronous interaction between the patient and the specialist designed to promote the treatment of patients with substance use disorder (SUD). This in turn helps solve privacy 
issues for SUD patients. On the other hand, the system does not serve as a substitute for face-to-face care. However, healthcare accessed by this technology is achieved in rural areas and to those patients who have difficulty moving, either by physical or personal barriers (Huskamp et al. 2018).

Electronic consultations (e-consults) have been used in the USA to improve access to specialty care. Another point in favor is the possibility of preventing and controlling infectious diseases (Strymish et al. 2017).

Another technology specification used by telemedicine in the USA is the control of therapeutic drug intake by wirelessly observed therapy (WOT), a patient monitoring system in which an edible intake sensor and a wearable external adhesive, both accompanied by a paired mobile device, digitally detect and record the patient's medication intake. This system supports daily adherence to medication in the treatment of tuberculosis, particularly (Browne et al. 2019). According to the authors, it is a secure system that does not require secondary interpretation or large transfers of data files and is available remotely. The authors point out that WOT should be tested in environments where tuberculosis treatment is costly, substantially supporting tuberculosis programs in low- and middle-income countries (Browne et al. 2019).

Digital technologies like mHealth, eHealth, and teleHealth have been employed in the use of telemedicine in the USA and are installed on mobile devices (phones, smartphones, and tablets) with internet access and telecommunications technologies. These technologies have ensured a better involvement in the treatment of patients, in addition to supporting communication between patients and health professionals. The characteristic scenario that corroborated global adherence (USA, South Africa, Cameroon, Peru, Uganda, Kenya, Botswana, and China) to the use of these technologies was the human immunodeficiency virus infection (HIV) epidemic.

In Ontario, Canada, the voice and video communication tools already established in the world, such as Skype and FaceTime, have been adopted to implement telemedicine. The feasibility of using this software provides privacy to patients during consultations, offers time savings, and reduces lost working days of patients. Parmar et al. (2014) state that delays in appointments and cancelation of consults have been reduced, with concomitant accessibility to specialized care; consequently, more patients were promptly evaluated, screened, and treated. The authors reported the inability to perform a complete physical examination, due to the quality of the equipment's image influencing the diagnosis. The use of telemedicine facilitated access to isolated patients (nursing home residents, incarcerated, and the population living in rural communities), those with infectious diseases (HIV, hepatitis $\mathrm{C}$, tuberculosis), or those with chronic diseases.

Still in Ontario (Canada), Chu et al. (2013) and Randle et al. (2018) reported the use of telemedicine in coping with epidemic outbreaks of H1N1 influenza and Zika virus, respectively. The Ontario Telehealth system is a free and confidential telemedicine service provided by the Ontario Ministry of Health and Long Term Care that allows Ontario residents to communicate with a registered nurse to answer medical or health questions at any time of the day or night. This system has the function of guiding and providing information to the population regarding the epidemic outbreaks of H1N1 influenza and the Zika virus, also contributing to the dissemination of preventive actions that reduce and even prevent the transmission of these infectious diseases.

In Australia, the use of Health Consultation Record + Health Aeromedical Logistics (HCR + HAL) technologies, an electronic health consultation record and database, has served thousands of Australians through telehealth consultations. The authors report that the reduction of dispensed medications is significant, promoting a reduction in the costs of health systems. This telemedicine apparatus was implemented to reach rural and remote populations with infectious diseases, respiratory tract diseases, skin diseases, and diseases of the circulatory system (Cherry et al. 2018).

The eHealth application implemented in Argentina consists of a Web-RTC (real-time communication) framework for high-quality transmission and audio and video performance to provide the service without compromising the security of the hospital network. With this infrastructure, the system avoids overcrowding in highly complex health institutions and reduces waiting times, reducing consultation delays. Besides, it avoids unnecessary referrals and prevents the spread of infection in waiting rooms. This system was created to support the prevention and treatment of upper respiratory tract infections during a seasonal epidemiological outbreak that can contribute to overcrowding and overload of the health system (Frid et al. 2019).

A telephone monitoring program that aims to report the processes used by the telemonitoring center (CTM) of UNIMED Belo Horizonte, Belo Horizonte (Brazil) was developed to support the customer with flu syndrome during the influenza A (H1N1) pandemic in 2009. At the time of inclusion of the client, the health professional applied a questionnaire that generated a score establishing a diagnosis and a follow-up plan according to the infectious situation: flu syndrome, flu syndrome with an epidemiological connection or risk factor, or flu syndrome with severity criterion or severe acute respiratory syndrome (SARS). All follow-up after registration was made by telephone calls by CTM. This program allowed the anticipation of the risks of disease injury and greater precautions of customers regarding transmission, being then considered an effective service in supporting the management of the crisis generated by this pandemic.

The literature demonstrates the use of telemedicine in other epidemics in Brazil, such as the Zika virus epidemic, dengue outbreak, and H1N1 influenza (Costa et al. 2014). The RIO 
SGB-ZIKA research network consists of a web conference via tele-education to prevent dengue outbreaks and a telephone monitoring program was applied in this context. The RIO SGB-ZIKA research network is a network that gathers more accurate epidemiological information on neurological diseases associated with the Zika virus in adults-including Guillain-Barré syndrome, meningoencephalitis, and transverse myelitis, as well as managing their treatment (Da Silva et al. 2016). The use of encrypted group messaging with smartphone applications (WhatsApp) allows groups of neurologists and researchers to instantly identify new cases and review and evaluate diagnostic tests such as nerve conduction, electromyography, and magnetic resonance imaging studies.

\section{Technologies used in telemedicine to combat COVID- 19: a systematic review}

After mapping the telemedicine panorama in the world to understand how the use of technology has worked in various scenarios, considerations about telemedicine in the context of COVID-19 must be contextualized.

Thirty-four telemedicine technologies were found to be used in the world specifically for COVID-19, one that is used in Brazil, according to data collected in the literature. This technology has been described as combating the pandemic of SARS-CoV-2 for the care, diagnosis, or treatment of patients with COVID-19 (or suspected COVID-19).

The importance of telemedicine in Brazil and around the world to assist in providing services to the most deprived populations or who live in remote places of difficult access is already notorious. Currently, the adoption of telemedicine has been increasingly necessary to ensure access to medical services in the current pandemic scenario, while at the same time unaffecting face-to-face care and allows health professionals to return attention to the most serious cases, whether caused by COVID-19, whether by other diseases, accidents, or other urgent medical needs.

The search for scientific articles resulted in a predominance of technologies used in the USA. The USA federal health insurance program, Medicare, has a broad telemedicine system, Medicare Telehealth Visits (Berg et al. 2020; Rogers et al. 2020; Tran et al. 2020), the Medicare Virtual Check-in (Berg et al. 2020; Rogers et al. 2020), the Medicare $e$-Visit (Berg et al. 2020; Lakkireddy et al. 2020; Rogers et al. 2020), and telecommunication platforms for virtual medical consultation and daily evaluation of patients under follow-up. Health insurance is intended for people over 65 years old, young people and children with disabilities, and people with endstage diseases (UNITED STATES OF AMERICA 2020a). The articles report the experience of physicians and other professionals in the distance care of their patients, such as diabetic patients with complications, patients with heart disease with newly implanted devices, among others. In general, the intent is to minimize the risk of these patients becoming infected with SARS-CoV-2 and to free up resources for the care of people with COVID-19.

Also, Cybercare is currently being developed in the United States, a tool that provides a network-based healthcare solution that decentralizes resources using information technology to provide medical care. A key concept of Cybercare is that instead of patients moving from remote areas to hospitals, information is transferred from a centralized area with specialists to remote areas with generalists and patients. The place of care moves from centralized hospitals to clinics and residences in the neighborhood; the provision of care goes from specialists to generalists; doctors promote prevention and treatment (Rosen et al. 2016).

Additionally, in the USA, some private health systems, such as Jefferson Health, Mont Sinai, Kaiser Permanente, Cleveland Clinic, Mercy Virtual Care Center, and Providence, for example, have their telemedicine technologies; others hire third-party programs such as Teladoc Health, My Health Online (Sutter Health), Sentara Mobile App (Sentara Healthcare), Aurora Health Care, Amwell for patients, Epic Telehealth, and Zoom for Healthcare (Berg et al. 2020; Dashraath et al. 2020; Grange et al. 2020; Hollander and Carr 2020). In general, these technologies rely on a mobile app to allow doctors and support teams to monitor patients who are at home. Some technologies allow the population to consult health information, locate clinics and hospitals, undergo screening, schedule new medical appointments (face-to-face or teleconsultations), or check their clinical history and access laboratory and imaging results, all to ensure maximum social isolation and maintain quality in care. Another example of this is My HealtheVet (Myers et al. 2020) and Veterans Affairs' virtual platform for the care of US war veterans whose goal is to provide medical and mental healthcare without the need for clinics, avoiding agglomerations.

The Attend Anywhere is a system with teleinformation, teleconsultation, and telediagnosis capabilities widely used in the UK and Australia. The technology allows collaboration between governments, universities, health systems, and hospitals, ensuring access to quality telemedicine to populations (Connor et al. 2020). During the COVID-19 pandemic, the system has been increasingly widespread and used to reduce patients' contact with health professionals. Also, in the UK, Microsoft Corporation made Microsoft Teams available for free with AccountGuard security for use by the NHS (Shanthanna et al. 2020). The job management and communication platform combine chats, video conferences, file storage, and application integration to facilitate the communication and work of doctors, researchers, and NHS staff in tackling the pandemic.

In the UK, there is currently a free smartphone app, called ClickClinica, used to try to increase the identification of major infectious diseases and other acute medical presentations and improve understanding of the clinical practice. The database 
generated from the use of the application can also answer new, dynamic, and targeted questions (Michael and Geleta 2013). When a new guideline is released, for example, for a new pandemic infection (such as the COVID-19 pandemic), this application has the potential to track, in real-time, the acceptance and overall use of the guideline.

In addition to the use of telemedicine as a form of access for the population, there is also the application of telemedicine for internal use in clinical and hospital environments, such as electronic medical records (telemedical records), for example, Epic Mobile Haiku and Epic Mobile Canto, or complete telecomputer telephony integration (tele-CTI) systems, such as Amwell Avizia (Berg et al. 2020), SafeWatch (Mercy Virtual Care Center), Electronic ICU (Sutter Health), and Sentara e-ICU (Sentara Healthcare) - integrated connectivity systems with a line of peripheral electromedical equipment for patient monitoring (Hollander and Carr 2020), verification of vital signs at a distance, access to medical records, and communication between professionals to limit the maximum number of the technical staff and health professionals with hospitalized patients. Also, in healthcare units, triage systems, such as Teletriage (inDoc) (Turer et al. 2020), are being used to quickly pre-evaluate patients and identify suspected patients of having COVID-19.

The review showed that six of the ten countries listed in the research are using relationship applications as a means of access and provision of health services. Apple FaceTime, Google Hangouts, Google Duo, Microsoft Skype, Cisco WebEx, WhatsApp, Facebook Messenger, WeChat, and email providers are public and private communication platforms for personal and business relationships that have tools for video conferencing, telephony and message chat, as well as sharing images, videos, audios, and documents. They are simple to use, widely disseminated, and have a friendly interface and high usability, allowing ease and agility in communication; however, they have not (or should not) be used for medical purposes as they do not meet most safety requirements. In contrast, the review showed that these applications are being used for teleinformation, query scheduling, teletriage, teleconsultation, and even telediagnosis (Calton et al. 2020; Dashraath et al. 2020; Davarpanah et al. 2020; Huang et al. 2020; Lakkireddy et al. 2020; Myers et al. 2020; Perez-Alba et al. 2020; Rogers et al. 2020; Rubin et al. 2020; Taheri et al. 2020; Turer et al. 2020; Yang et al. 2020; Zhou et al. 2020).

In India, for example, custom mobile vans with computer and video applications (Skype) are widely used to transmit retinal images to ophthalmologists and to consult diabetologists specialists in a tertiary care center in disadvantaged areas of Delhi (Ghosh et al. 2020; Jakhar et al. 2020). Such a system has shown increasing success in screening and managing diabetes using telemedicine in the current pandemic scenario.

Although they are not platforms dedicated to telemedicine and have a low (or very low) level of digital security, due to the urgency and emergency in healthcare and services, the regulatory organizations of the six respective countries have liberalized the use of these relationship applications during the SARS-CoV-2 pandemic, such as the United States Department of HHS. Apple Watch and KardiaMobile (AliveCor)_devices for reading, monitoring, and recording electrocardiographic signals for personal use (Rubin et al. 2020) _ are other examples of unconventional technology that are being accepted by healthcare professionals for monitoring patients in remote follow-up during the pandemic.

In Brazil, the Coronavirus SUS smartphone application provides a directory of questions that directs intervention flows and guidance regarding COVID-19 (Posenato 2020). It can also be used to provide evidence-based information on the spread of the pandemic. If the application indicates probable infection, patients are referred to the nearest emergency department or health unit for testing, improving the efficiency and effectiveness of the traditional healthcare environment. In addition, as it provides evidence-based pandemic information, it reduces the prevalence of fake news and consequently helps reduce panic. The combination of prevention, screening, and information in an application has become a telemedicine tool, reducing the demands of the public health system in Brazil and, in turn, helping to prevent the collapse of the health system.

In addition to causing various physical health problems, the review showed that COVID-19 has also caused many psychological problems. Mental health apps such as BetterHelp, Moodgym, E-couch, Beyond, Blue, HeadSpace, ROUK, and Black Dog Institute have proven important in the care of depression, stress, anxiety, trauma, and eating disorder, helping daily health professionals, patients diagnosed with COVID-19, relatives of diagnosed patients, and some people facing social isolation with difficulty (Zhou et al. 2020). In the UK, to maximize social isolation efforts, there are also virtual veterinary consultation applications with care by local and international veterinarians where pet assessment is made, rapid diagnosis, and, if necessary, face-to-face care scheduling with a home visit or referral to veterinary clinics or hospitals (Waters 2020).

In the study by (Wong et al. 2020), a wearable signal monitor is presented, capable of tracking heart rate, heart rate variability, blood oxygen saturation, blood pulse wave, resting respiratory rate, blood perfusion of skin, activity, steps, skin temperature, barometric pressure, and electrodermal activity. The obtained physiological parameters are transferred automatically in real time through a smartphone application. The results are displayed to the doctor on a web-based panel. Physiological parameters are processed to detect physiological changes, thus allowing doctors to intervene immediately and request diagnostic tests for COVID-19 infection through instant communication (Wong et al. 2020).

Table 2 shows a summary of the technologies used in telemedicine in the fight against COVID-19 and the benefits for their countries. 
Table 2 Technologies used in telemedicine in the fight against COVID-19 and the main benefits

Technology
Medicare Telehealth Visits, Medicare Virtual Check-in, Medicare e-Visit
USA
Cybercare_USA
Teladoc Health, My Health Online (Sutter Health), Sentara Mobile App
(Sentara Healthcare), Aurora Health Care, Amwell for patients, Epic
Telehealth, and Zoom for Healthcare-USA
HealtheVet
Attend Anywhere-UK and Australia
Microsoft Teams with AccountGuard-UK
ClickClinica—UK

ClickClinica-UK

Epic Mobile Haiku and Epic Mobile Canto; or complete tele-CTI systems, such as Amwell Avizia, SafeWatch (Mercy Virtual Care Center), Electronic ICU (Sutter Health) and Sentara e-ICU (Sentara Healthcare), Teletriage

Apple FaceTime, Google Hangouts, Google Duo, Microsoft Skype, Cisco WebEx, WhatsApp, Facebook Messenger, WeChat, and email

Custom mobile vans with computer and video applications (Skype) - India Apple Watch and KardiaMobile-USA

Coronavirus SUS smartphone-Brazil

BetterHelp, Moodgym, E-couch, Beyond, Blue, HeadSpace, ROUK, and Black Dog Institute

Wearable signal monitor
Benefits

The intention is to minimize the risk of diabetic patients with complications, patients with heart disease with newly implanted devices, avoiding contamination by SARS-CoV-2, and to free up resources for the care of people with COVID-19

The place of care moves from centralized hospitals to clinics and residences in the neighborhood; the provision of care goes from specialists to generalists; doctors promote prevention and treatment

These technologies ensure maximum social isolation and maintain quality in care allowing the patient to have access to diagnoses, exam results, schedule appointments, among others.

This approach avoids agglomerations

Used to reduce patients' contact with health professionals

Used to facilitate the communication and work of doctors, researchers, and NHS staff in tackling the pandemic

This application has the potential to track, in real-time, the acceptance and overall use of the new guidelines.

Used to quickly pre-evaluate patients and identify suspected patients of having COVID-19

Used for teleinformation, query scheduling, teletriage, teleconsultation, and even telediagnosis

Success in screening and managing diabetes

Accepted by healthcare professionals for monitoring patients in remote follow-up during the pandemic

This technology reduces the demands of the public health system in Brazil and, in turn, helps preventing the collapse of the health system.

These applications have proven important in the care of depression, stress, anxiety, trauma, and eating disorder; helping daily health professionals, patients diagnosed with COVID-19, relatives of diagnosed patients, and some people facing social isolation with difficulty.

The technology allows doctors to intervene immediately and order diagnostic tests for COVID-19 infection via instant communication

\section{Telemedicine considerations and legal aspects}

COVID-19 has already infected more than $98,817,191$ people, in addition to causing the death of around 2,100,000 people by January 2021 (Johns Hopkins 2021). This number of people infected with varying degrees of severity makes medical health facilities overcrowded and significantly affects global health systems. Telemedicine can minimize these effects, in addition to ensuring the health of professionals and the population. One of the great advantages of telemedicine at that time is the possibility of access to health services for people who are quarantined.

The COVID-19 pandemic is likely to modify and bring about important changes in the way health services are currently viewed, especially in the doctor-patient relationship. There are still no specific vaccines or medicines for the treatment of COVID-19; the best strategy currently used is prevention through the use of masks, continually washing hands with soap and water, cleaning with $70 \%$ alcohol, and mainly maintaining social distance, which includes the health professional and the patient. In this situation, telemedicine allows the performance of various clinical activities and at the same time maintains the safety of the health professional and the patient.

The use of telemedicine has several barriers that can limit or even prevent its use. Several of these barriers can be cited such as adequate infrastructure, which includes, among others, the speed available for the internet, network signal, and equipment. In addition, the system is often difficult to use and there is a lack of familiarity between the patient and the health professional with the technology, requiring training between the parties involved. However, in addition to these physical, psychological, cultural, and knowledge barriers, there are barriers imposed by the laws of each country, which are important, but in some cases are more limiting than necessary.

Faced with the new coronavirus pandemic, telemedicine, mainly video consultations, was promoted and expanded, 
especially in the USA and the UK. Telemedicine services face several legal and regulatory challenges; however, in recent months, there has been a loosening of state, federal, and international laws and regulations in order to promote greater adoption of the use of remote services.

Most countries lack laws to authorize, integrate, and reimburse telemedicine services, including in emergency situations. In Brazil, the reimbursement issue was not addressed yet, being limited to financial support to telehealth services (Silva et al. 2015b).

At this moment, two possibilities are available for patients: telemedicine direct to the consumer with private providers and free solutions, mainly from North American companies (for example, WhatsApp, Skype, Facetime) which, while not respecting the privacy and data security requirements, can be a solution to support and alleviate health services (Ohannessian et al. 2020). However, at this time of pandemic and others that may arise, it is important that issues related to data protection, which often limit the use of telemedicine, are addressed for the good of the population. The answer to the question "how much more important is data protection than health?" is not simple and requires much discussion. The answer to this question is diverse among countries, some have made the legislation more flexible to meet the health needs of the population, other countries already have the looser rule regarding data protection, and others have remained inflexible. In this regard, we agree with Ekong et al. (2020), in the sense data protection is extremely important, but that it can be reconciled with the use of telemedicine.

It is necessary to address the concerns about protecting patient data and promoting equity in health services, to ensure the improvement of telemedicine practice (Mehta 2014).
In Brazil, medical care at distance, using telemedicine or another method, is provided under the regulation of the CFM. Article 37 of CFM Resolution 1931/2009 deals with remote medical care: "It is forbidden for the physician to prescribe treatment or other procedures without direct examination of the patient, except in cases of urgency or emergency and proven impossibility to perform it, and, in this case, do so immediately after the impediment ceases" (BRASIL 2009). However, the CFM resolution that regulates telemedicine is old and has been in force since 2002. The CFM has issued a new resolution, Resolution 2227/2018, which was widely criticized and was repealed by resolution $2228 / 2019$. Thus, Resolution no.1643/2002 is still in effect. Therefore, there is a need for changes in this resolution due to advances that have occurred in technology, in the data protection laws of the population, and to face pandemics in a more concrete way, as is happening in more developed regions, mainly the USA and the UK.

In this scenario, the results of the systematic review and assessments of legal aspects in different countries point to the topics, shown in Table 3, which must be addressed, discussed, and urgently resolved to combat this and other pandemics, in addition to existing diseases during a normal period.

\section{Conclusion}

This systematic review showed that telemedicine represents an important role in emergency cases since it allows care in remote locales with lower costs for the patient. Particularly, in pandemic situations, such as the COVID-19, we are experiencing the benefits of telemedicine are even greater, just considering the

Table 3 Topics and motivation for technical and law changes to combat pandemics and existing diseases

\begin{tabular}{|c|c|}
\hline Topics & Motivation \\
\hline \multicolumn{2}{|l|}{ Technical questions } \\
\hline Training & The lack of technical knowledge of doctors and patients about the technology used \\
\hline Infrastructure & To make equipment and network speed suitable for telemedicine \\
\hline Data safety & To keep patient and healthcare professional data safe (personal and healthcare) \\
\hline Friendly interface & To facilitate the use of technology \\
\hline \multicolumn{2}{|l|}{ Legal issues } \\
\hline Ethical questions & $\begin{array}{l}\text { The importance of ethical issues in telemedicine is unquestionable since data from patients and doctors are transmitted by } \\
\text { telecommunications systems, especially the Internet. }\end{array}$ \\
\hline Reimbursement & $\begin{array}{l}\text { This is a topic that has not even been addressed in Brazil and that can reduce the need for ICU beds for the treatment of COVID-19 } \\
\text { or other diseases. }\end{array}$ \\
\hline Data safety & $\begin{array}{l}\text { In this topic, it is important to analyze when the security of personal data begins to interfere negatively in the benefits that } \\
\text { telemedicine can bring to individual and collective health, assessing the limits to avoid any damage to the security of personal } \\
\text { data or to the health. }\end{array}$ \\
\hline $\begin{array}{l}\text { Modernization of } \\
\text { laws }\end{array}$ & $\begin{array}{l}\text { Brazil has a resolution that deals with the use of old telemedicine, more specifically from the year } 2002 \text {, obviously that behavioral } \\
\text { and technology changes have occurred. Thus, there is an urgent need to modernize the laws, in this case, of Brazil. }\end{array}$ \\
\hline
\end{tabular}


need for social distancing and the limited capacity of hospitalizations present in all countries. In such cases, telemedicine can prevent possible contagion and also prevent health services from becoming overloaded. However, there are limitations about the application of telemedicine and at times when the answer should be given quickly to society, these limitations can impact on benefits that telemedicine can offer. A very important limitation is the legislation related to telemedicine, which in several countries of the world has been relaxed. Thus, telemedicine has been gaining space in health, just as the relevant legislation has been modified and modernized over time.

In the face of an environment of chaos created due to the COVID-19 pandemic, there was a need to loosen and change some regulatory issues in the practice of telemedicine, as a way of avoiding crowds of patients in health services, avoiding possible contagions, in addition to increasing access to health services due to geographical and economic barriers, tracking and detecting possible cases of the new coronavirus, and monitoring patients with mild symptoms of the disease.

Acknowledgments The authors would like to thank the National Council for Scientific and Technological Development (CNPq), Coordination of Improvement of Higher-Level Personnel (CAPES Program CAPES/ DFATD-88887.159028/2017-00, Program CAPES/COFECUB88881.370894/2019-01), and Foundation for Research Support of the State of Minas Gerais (FAPEMIG-APQ-00942-17). A. O. Andrade and A. A. Pereira, are Fellows of CNPq, Brazil (304818/2018-6 and 310911/ 2017-6, respectively).

\section{Declarations}

Conflict of interest The authors declare no conflict of interest.

\section{References}

Ateriya N, Saraf A, Meshram VP, Setia P. Telemedicine and virtual consultation: the Indian perspective. Natl Med J India. 2018;31: 215-8. https://doi.org/10.4103/0970-258X.258220.

Bakibinga-Gaswaga E, Bakibinga S, Bakibinga DBM, Bakibinga P. Digital technologies in the COVID-19 responses in sub-Saharan Africa: policies, problems and promises. Pan Afr Med J. 2020;35: 1-3. https://doi.org/10.11604/pamj.2020.35.2.23456.

Barit A. The apps are coming! But will they be legal South Africa? South African Med J. 2019;109:150-1. https://doi.org/10.7196/SAMJ. 2019.v109i3.13812.

Baumann BC, MacArthur KM, Michalski JM. The importance of temporary telehealth parity Laws to improve public health during COVID19 and future pandemics. Int J Radiat Oncol Biol Phys. 2020;108: 362-3. https://doi.org/10.1016/j.ijrobp.2020.05.039.

Berg EA, Picoraro JA, Miller SD, Srinath A, Franciosi JP, Hayes CE, et al. COVID-19 - a guide to rapid implementation of telehealth services. J Pediatr Gastroenterol Nutr. 2020;70:734-40. https://doi. org/10.1097/MPG.0000000000002749.
BRASIL. RESOLUÇÃO CFM 1.643/2002. 2002:2. [cited 2020 June 1]. Available from: https://sistemas.cfm.org.br/normas/visualizar/ resolucoes/BR/2002/1643.

BRASIL. Resolução CFM No 1931/2009. 2009. [cited 2020 June 1]. Available from: http://portal.cfm.org.br/index.php?option=com content\&id=20670:resolucao-cfm-no-19312009.

BRASIL. MINISTÉRIO DA SAÚDE. PORTARIA N ${ }^{\circ}$ 467, DE 20 DE MARÇO DE 2020 - DOU - Imprensa Nacional. 2020a. [cited 2020 June 1]. Available from: http://www.in.gov.br/en/web/dou/-/ portaria-n-467-de-20-de-marco-de-2020-249312996.

BRASIL. LEI N ${ }^{\circ}$ 13.989, DE 15 DE ABRIL DE 2020 - LEI N ${ }^{\circ} 13.989$, DE 15 DE ABRIL DE 2020 - DOU - Imprensa Nacional. 2020b. [cited 2020 June 1]. Available from: http://www.in.gov.br/en/web/ dou/-/lei-n-13.989-de-15-de-abril-de-2020-252726328.

Breen GM, Matusitz J. An evolutionary examination of telemedicine: a health and computer-mediated communication perspective. Soc Work Public Health. 2010;25:59-71. https://doi.org/10.1080/ 19371910902911206.

Browne SH, Umlauf A, Tucker AJ, Low J, Moser K, Garcia JG, et al. Wirelessly observed therapy compared to directly observed therapy to confirm and support tuberculosis treatment adherence: a randomized controlled trial. PLoS Med. 2019;16:e1002891. https://doi.org/ 10.1371/journal.pmed.1002891.

Calleja-Castillo JM, Gonzalez-Calderon G. WhatsApp in stroke systems: current use and regulatory concerns. Front Neurol. 2018;9. https:// doi.org/10.3389/fneur.2018.00388.

Calton B, Abedini N, Fratkin M. COVID-19 for fast track publication telemedicine in the time of coronavirus. J Pain Symptom Manag. 2020;60:e12-4. https://doi.org/10.1016/j.jpainsymman.2020.03. 019.

Chaet D, Clearfield R, Sabin JE, Skimming K. Ethical practice in telehealth and telemedicine. J Gen Intern Med. 2017;32:1136-40. https://doi.org/10.1007/s11606-017-4082-2.

Cherry JJ, Rich WC, McLennan PL. Telemedicine in remote Australia: the Royal Flying Doctor Service (RFDS) Medical Chest Program as a marker of remote health. Rural Remote Health. 2018;18:4502. https://doi.org/10.22605/RRH4502.

Chu A, Savage R, Whelan M, Rosella LC, Crowcroft NS, Willison D, et al. Assessing the relative timeliness of Ontario's syndromic surveillance systems for early detection of the 2009 influenza H1N1 pandemic waves. Can J Public Heal. 2013;104:340-7. https://doi. org/10.17269/cjph.104.3721.

Connor MJ, Winkler M, Miah S. COVID-19 pandemic - is virtual urology clinic the answer to keeping the cancer pathway moving? BJU Int. 2020;125:E3-4. https://doi.org/10.1111/bju.15061.

Costa C d A, Petrucio WS, Rodrigues PM d A, Lages RO, Wen CL. Effectiveness of practices for Web Conferencing Teleducation to combat dengue in the State of Amazonas, Brazil. J Heal Informatics. 2014;6:15-8.

Courtney J. H.R.748 - 116th Congress (2019-2020): CARES Act Congress.gov | Library of Congress. 2020. [cited 2020 November 27]. Available from: https://www.congress.gov/bill/116th-congress/ house-bill/748.

Da Silva IRF, Frontera JA, Do Nascimento OJM. News from the battlefront: Zika virus-associated Guillain-Barré syndrome in Brazil. Neurology. 2016;87:e180-1. https://doi.org/10.1212/WNL. 0000000000003024.

Dashraath P, Lin J, Wong J, Xian M, Lim K, Li M, et al. Coronavirus disease 2019 (COVID-19) pandemic and pregnancy. Am J Obstet Gynecol. 2020. https://doi.org/10.1016/j.ajog.2020.03.021.

Davarpanah AH, Mahdavi A, Sabri A, Langroudi F, Kahkouee S, Haseli S, et al. CASE STUDIES IN CLINICAL PRACTICE MANAGEMENT novel screening and triage strategy in Iran during deadly coronavirus disease 2019 (COVID-19) epidemic: value of 
humanitarian teleconsultation service. J Am Coll Radiol. 2020;17: 734-8. https://doi.org/10.1016/j.jacr.2020.03.015.

Dickens BM, Cook RJ. Legal and ethical issues in telemedicine and robotics. Int J Gynecol Obstet. 2006;94:73-8. https://doi.org/10. 1016/j.ijgo.2006.04.023.

Ekong I, Chukwu E, Chukwu M. COVID-19 mobile positioning data contact tracing and patient privacy regulations: exploratory search of global response strategies and the use of digital tools in Nigeria. JMIR MHealth UHealth. 2020;8:1-7. https://doi.org/10.2196/ 19139.

Ellimoottil C, Skolarus T, Gettman M, Boxer R, Kutikov A, Lee BR, et al. Telemedicine in urology: state of the art. Urology. 2016;94:10 6. https://doi.org/10.1016/j.urology.2016.02.061.

Emergency Medicine Telemedicine. EMT. Ann. Emerg. Med. 2016;67, Mosby Inc.;:687-9. https://doi.org/10.1016/j.annemergmed.2016. 03.014 .

FRANCE. Code de la santé publique | Legifrance. 2019. [cited 2020 June 1]. Available from: https://www.legifrance.gouv.fr/ affichCode.do?cidTexte=LEGITEXT000006072665.

FRANCE. Décret n 2020-227 du 9 mars 2020 adaptant les conditions du bénéfice des prestations en espèces d'assurance maladie et de prise en charge des actes de télémédecine pour les personnes exposées au covid-19 | Legifrance. 2020. [cited 2020 June 1]. Available from: https://www.legifrance.gouv.fr/affichTexte.do?cidTexte $=$ LEGITEXT000041704880\&dateTexte $=20200517$.

Frid SA, Ratti MFG, Pedretti A, Pollan J, Martínez B, Abreu AL, et al. Telemedicine for upper respiratory tract infections during $2018 \mathrm{ep}-$ idemiological outbreak in South America. Stud Health Technol Inform. 2019;264:586-90. https://doi.org/10.3233/SHTI190290.

Ghosh A, Gupta R, Misra A. Telemedicine for diabetes care in India during COVID19 pandemic and national lockdown period: guidelines for physicians. Diabetes Metab Syndr Clin Res Rev. 2020;14: 273-6. https://doi.org/10.1016/j.dsx.2020.04.001.

Gioia G, Salducci M. Medical and legal aspects of telemedicine in ophthalmology. Rom J Ophthalmol. 2019;63:197-207. https://doi.org/ 10.22336/rjo.2019.31.

Goodini A, Torabi M, Goodarzi M, Safdari R, Darayi M, Tavassoli M, et al. The simulation model of teleradiology in telemedicine project. Health Care Manag (Frederick). 2015;34:69-75. https://doi.org/10. 1097/HCM.0000000000000049.

Grange ES, Neil EJ, Stoffel M, Singh AP, Tseng E, Resco-Summers K, et al. Responding to COVID-19: the UW medicine information technology services experience. Appl Clin Inform. 2020;11:26575. https://doi.org/10.1055/s-0040-1709715.

Gulyaeva N, Bakhtiozina A, Spitsyna N, Spiridonova N. Russian regulatory trends in the pharma industry due to COVID-19 - Hogan Lovells Engage. 2020. [cited 2020 November 27]. Available from: https://www.engage.hoganlovells.com/knowledgeservices/news/ russian-regulatory-trends-in-the-pharma-industry-in-light-of-theoutbreak-of-covid-19.

Gupta A, Sao D. The constitutionality of current legal barriers to telemedicine in the United States: analysis and future directions of its relationship to national and international health care reform, Health Matrix Clevel. 2011;21:385-442.

Hersh W, Helfand M, Wallace J, Kraemer D, Patterson P, Shapiro S, et al. A systematic review of the efficacy of telemedicine for making diagnostic and management decisions. J Telemed Telecare. 2002;8:197-209. https://doi.org/10.1258/135763302320272167.

Hollander JE, Carr BG. Virtually perfect? telemedicine for Covid-19. N Eng1 J Med. 2020;382:1679-81. https://doi.org/10.1056/ NEJMp2003539.

Hong Y-R, Lawrence J, Williams D Jr, Mainous A III. Population-level interest and telehealth capacity of US hospitals in response to COVID-19: cross-sectional analysis of Google Search and National Hospital Survey Data. JMIR Public Heal Surveill. 2020;6:e18961. https://doi.org/10.2196/18961.
Huang S, Xiao Y, Yan L, Deng J, He M, Lu J, et al. Implications for online management: two cases with COVID-19. Telemed e-Health. 2020;26:487-94. https://doi.org/10.1089/tmj.2020.0066.

Huskamp HA, Busch AB, Souza J, Uscher-Pines L, Rose S, Wilcock A, et al. How is telemedicine being used in opioid and other substance use disorder treatment? Health Aff. 2018;37:1940-7. https://doi.org/ 10.1377/hlthaff.2018.05134.

Jakhar D, Kaul S, Kaur I. WhatsApp messenger as a teledermatology tool during coronavirus disease (COVID-19): from bedside to phoneside. Clin Exp Dermatol. 2020;45:739-40. https://doi.org/10.1111/ ced.14227.

Johns Hopkins. COVID-19 Map - Johns Hopkins Coronavirus Resource Center. 2021. [cited 2021 January 24]. Available from: https:// coronavirus.jhu.edu/map.html.

Kahn JM. Virtual visits - confronting the challenges of telemedicine. N Engl J Med. 2015;372:1684-5. https://doi.org/10.1056/ NEJMp1500533.

Karyagina EN, Sitdikova ARI. Telemedicine: The Concept and Legal Regulation in Russia, Europe, and USA. J Hist Cult Art Res. 2019;8:417. https://doi.org/10.7596/taksad.v8i4.2390.

Kim JE, Song YM, Park JH, Lee JR. Attitude of Korean primary care family physicians towards telehealth. Korean J Fam Med. 2011;32: 341-51. https://doi.org/10.4082/kjfm.2011.32.6.341.

Lakkireddy DR, Chung MK, Gopinathannair R, Patton KK, Gluckman TJ, Turagam M, et al. Guidance for Cardiac Electrophysiology During the Coronavirus (COVID-19) Pandemic from the Heart Rhythm Society COVID-19 Task Force; Electrophysiology Section of the American College of Cardiology; and the Electrocardiography and Arrhythmias Committee of. Hear Rhythm. 2020. https://doi.org/10.1016/j.hrthm.2020.03.028.

Langarizadeh M, Moghbeli F, Aliabadi A. Application of ethics for providing telemedicine services and information technology. Med Arch (Sarajevo, Bosnia Herzegovina). 2017;71:351-5. https://doi.org/10. 5455/medarh.2017.71.351-355.

Li H, Zheng S, Liu F, Liu W, Zhao R. Fighting against COVID-19: innovative strategies for clinical pharmacists. Res Soc Adm Pharm. 2020;17:1813-8. https://doi.org/10.1016/j.sapharm.2020. 04.003.

Lilly CM, Zubrow MT, Kempner KM, Reynolds HN, Subramanian S, Eriksson EA, et al. Critical care telemedicine: evolution and state of the art. Crit Care Med. 2014;42:2429-36. https://doi.org/10.1097/ CCM.0000000000000539.

Lindenbraten AP. [The Federal Law "On the fundamentals of health protection of citizen in the Russian Federation" and the issues of management of medical care quality]. Probl sotsial'noi Gig Zdr i Istor meditsiny. 2012:3-5.

Matusitz J, Breen GM. E-health: a new kind of telemedicine. Soc Work Public Health. 2008;23:95-113. https://doi.org/10.1300/ J523v23n01_06.

Mehta SJ. Telemedicine's potential ethical pitfalls. Virtual Mentor. 2014;16:1014-7. https://doi.org/10.1001/virtualmentor.2014.16.12. msoc1-1412.

Michael BD, Geleta D. Development of ClickClinica: a novel smartphone application to generate real-time global disease surveillance and clinical practice data. BMC Med Inform Decis Mak. 2013;13:70. https://doi.org/10.1186/1472-6947-13-70.

Moazzami B, Razavi-Khorasani N, Dooghaie Moghadam A, Farokhi E, Rezaei N. COVID-19 and telemedicine: immediate action required for maintaining healthcare providers well-being. J Clin Virol. 2020;126:104345. https://doi.org/10.1016/j.jcv.2020.104345.

Moher D, Shamseer L, Clarke M, Ghersi D, Liberati A, Petticrew M, et al. Preferred reporting items for systematic review and meta-analysis protocols (PRISMA-P) 2015 statement. Rev Esp Nutr Humana y Diet. 2016;20:148-60. https://doi.org/10.1186/2046-4053-4-1. 
Mort M, May CR, Williams T. Remote doctors and absent patients: acting at a distance in telemedicine? Sci Technol Hum Values. 2003;28:274-95. https://doi.org/10.1177/0162243902250907.

Myers US, Birks A, Grubaugh AL, Axon RN. Flattening the curve by getting ahead of it: how the VA healthcare system is leveraging telehealth to provide continued access to care for rural veterans. J Rural Heal. 2020. https://doi.org/10.1111/jrh.12449.

Neville CW. Telehealth: a balanced look at incorporating this technology into practice. SAGE Open Nurs. 2018;4:237796081878650. https:// doi.org/10.1177/2377960818786504.

Ohannessian R, Duong TA, Odone A. Global telemedicine implementation and integration within health systems to fight the COVID-19 pandemic: a call to action. JMIR Public Heal Surveill. 2020;6: e18810. https://doi.org/10.2196/18810.

Oudshoorn N. Diagnosis at a distance: the invisible work of patients and healthcare professionals in cardiac telemonitoring technology. Sociol Heal Illn. 2008;30:272-88. https://doi.org/10.1111/j.14679566.2007.01032.x.

Parmar P, Mackie D, Varghese S, Cooper C. Use of telemedicine technologies in the management of infectious diseases: a review. Clin Pract. 2014. https://doi.org/10.1093/cid/ciu1143.

Perez-Alba E, Nuzzolo-Shihadeh L, Espinosa-Mora JE, An CamachoOrtiz A. Use of self-administered surveys through QR code and same center telemedicine in a walk-in clinic in the era of COVID19. J Am Med Informatics Assoc. 2020;27:1-2. https://doi.org/10. 1093/jamia/ocaa054.

Portnoy J, Waller M, Elliott T. Telemedicine in the era of COVID-19. J Allergy Clin Immunol Pract. 2020;8:1489-91. https://doi.org/10. 1016/j.jaip.2020.03.008.

Posenato GL. How Brazil can hold back COVID-19. Epidemiol Serv Saude, Brasília. 2020;29:1-8. https://doi.org/10.5123/S167949742020000200023.

Randle J, Nelder M, Sider D, Hohenadel K. Characterizing the health and information-seeking behaviours of Ontarians in response to the Zika virus outbreak. Can J Public Heal. 2018;109:99-107. https://doi.org/ 10.17269/s41997-018-0026-9.

Raposo VL. Telemedicine: the legal framework (or the lack of it) in Europe. GMS Health Technol Assess. 2016;12:Doc03. https://doi. org/10.3205/hta000126.

Rockwell KL, Gilroy AS. Incorporating telemedicine as part of COVID19 outbreak response systems. Am J Manag Care. 2020;26:147-8. https://doi.org/10.37765/ajmc.2020.42784.

Rogers LC, Lavery LA, Joseph WS, Armstrong DG. All feet on deck-the role of podiatry during the COVID-19 pandemic: preventing hospitalizations in an overburdened healthcare system, reducing amputation and death in people with diabetes. J Am Podiatr Med Assoc. 2020. https://doi.org/10.7547/20-051.

Roine R, Ohinmaa A, Hailey D. Assessing telemedicine: a systematic review of the literature. CMAJ. 2001;165:765-71. https://doi.org/ 10.1136/bmj.323.7312.557.

Rosen JM, Kun L, Mosher RE, Grigg E, Merrell RC, Macedonia C, et al. Cybercare 2.0: meeting the challenge of the global burden of disease in 2030. Health Technol (Berl). 2016;6:35-51. https://doi.org/10. 1007/s12553-016-0132-8

Rubin GA, Biviano A, Dizon J, Yarmohammadi H, Ehlert F, Saluja D, et al. Performance of electrophysiology procedures at an academic medical center amidst the 2020 coronavirus (COVID-19) pandemic. J Cardiovasc Electrophysiol. 2020. https://doi.org/10.1111/jce. 14493.

Serper M, Volk ML. Current and future applications of telemedicine to optimize the delivery of care in chronic liver disease. Clin Gastroenterol Hepatol. 2018;16:157-161.e8. https://doi.org/10. 1016/j.cgh.2017.10.004.

Shanthanna H, Strand NH, Provenzano DA, Lobo CA, Eldabe S, Bhatia A, et al. Caring for patients with pain during the COVID -19 pandemic: consensus recommendations from an international expert panel. Anaesthesia. 2020;75:935-44. https://doi.org/10.1111/anae. 15076.

Silva E, Garcia L, Terra J. A comparison of telehealth programs between the USA and Brazil: a legal perspective. Smart Homecare Technol TeleHealth. 2015a;3:139. https://doi.org/10.2147/shtt.s64447.

Silva E, Garcia L, Terra J. A comparison of telehealth programs between the USA and Brazil: a legal perspective. Smart Homecare Technol TeleHealth. 2015b;139. https://doi.org/10.2147/shtt.s64447.

Singh B, Ryan H, Kredo T, Chaplin M, Fletcher T. Chloroquine or hydroxychloroquine for prevention and treatment of COVID-19. Cochrane Database Syst Rev. 2020. https://doi.org/10.1002/ 14651858.CD013587.

Smith AC, Thomas E, Snoswell CL, Haydon H, Mehrotra A, Clemensen $\mathrm{J}$, et al. Telehealth for global emergencies: implications for coronavirus disease 2019 (COVID-19). J Telemed Telecare. 2020. https:// doi.org/10.1177/1357633X20916567.

SOUTH AFRICA. Health Professions Council of South Africa. Conduct and Ethics. Ethical guidelines for good practice in the health care professions. 2019. [cited 2020 June 1]. Available from: https:// www.hpcsa.co.za/?contentld=79.

Spradley P. Telemedicine: The Law is the Limit. Tulane Journal of Technology and Intellectual Property. 2011; 14:307-33. [cited 2020 June 1]. Available from: https://journals.tulane.edu/TIP/ article/view/2605.

Strymish J, Gupte G, Afable MK, Gupta K, Kim EJ, Vimalananda V, et al. Electronic consultations (E-consults): advancing infectious disease care in a large veterans affairs healthcare system. Clin Infect Dis Br Rep • CID. 2017;2017:1123-8. https://doi.org/10. 1093/cid/cix058

Sun S, Yu K, Xie Z, Pan X. China empowers Internet hospital to fight against COVID-19. J Inf Secur. 2020;81:e67-8. https://doi.org/10. 1016/j.jinf.2020.03.061

Taheri MS, Falahati F, Radpour A, Karimi V, Sedaghat A, Karimi MA. Role of social media and telemedicine in diagnosis \& management of COVID-19; an experience of the iranian society of radiology. Arch Iran Med. 2020;23:285-6. https://doi.org/10.34172/aim. 2020.15 .

Tidy J. Coronavirus: Israel enables emergency spy powers. BBC News. 2020. [cited 2020 November 27]. Available from: https://www.bbc. com/news/technology-51930681.

Tran DL, Lai SR, Salah RY, Wong AY, Bryon JN, Mckenna MC, et al. Rapid De-escalation and triaging patients in community-based palliative care. J Pain Symptom Manag. 2020;60:e45-7. https://doi.org/ 10.1016/j.jpainsymman.2020.03.040.

Tuckson RV, Edmunds M, Hodgkins ML. Telehealth. N Engl J Med. 2017;377:1585-92. https://doi.org/10.1056/NEJMsr1503323.

Turer RW, Jones I, Rosenbloom ST, Slovis C, Ward MJ. Electronic personal protective equipment: a strategy to protect emergency department providers in the age of COVID-19. J Ofthe Am Med Informatics Assoc. 2020;27:967-71. https://doi.org/10.1093/jamia/ ocaa048.

UNITED STATES OF AMERICA. Bill Text - AB-415 Healing arts: telehealth. 2011. [cited 2020 June 1]. Available from: https:// leginfo.legislature.ca.gov/faces/billTextClient.xhtml?bill_id= 201120120 AB415.

UNITED STATES OF AMERICA. RCW 74.09.325: Reimbursement of a health care service provided through telemedicine or store and forward technology-Report to the legislature. 2017. [cited 2020 June 1]. Available from: https://app.leg.wa.gov/rcw/default.aspx? cite $=74.09 .325$.

UNITED STATES OF AMERICA. Medicare.gov: the official U.S. government site for Medicare | Medicare. 2020a. [cited 2020 June 2]. Available from: https://www.medicare.gov/.

UNITED STATES OF AMERICA. Public Law 116-123 - Coronavirus Preparedness and Response Supplemental Appropriations Act, 2020 - Content Details - PLAW-116publ123. 2020b. [cited 2020 June 1]. 
Available from: https://www.govinfo.gov/app/details/PLAW116 publ123.

Vokinger KN, Nittas V, Witt CM, Fabrikant SI, Von Wyl V. Digital health and the COVID-19 epidemic: an assessment framework for apps from an epidemiological and legal perspective. Swiss Med Wkly. 2020;150:1-9. https://doi.org/10.4414/smw.2020.20282.

Waters A. Telemedicine services thrive during Covid-19. Vet Rec. 2020;365. https://doi.org/10.1136/vr.m1231.

WHO. Global Observatory for eHealth Series, 2. Telemedicine: opportunities and developments in Member States, report on the second global survey on eHealth. 2010. [cited 2020 June 1]. Available from: https://www.who.int/goe/publications/goe_telemedicine_2010.pdf.

Wong CK, Ho DTY, Tam AR, Zhou M, Lau YM, Tang MOY, et al. Artificial intelligence mobile health platform for early detection of COVID-19 in quarantine subjects using a wearable biosensor: protocol for a randomised controlled trial. BMJ Open. 2020;10:1-5. https://doi.org/10.1136/bmjopen-2020-038555.

World Health Organization (WHO). Coronavirus. (WHO), World Heal Organ. 2020. [cited 2020 May 8]. Available from: https://www. who.int/health-topics/coronavirus\#tab=tab_1.
Wright JH, Caudill R. Remote treatment delivery in response to the COVID-19 pandemic. Psychother Psychosom. 2020;89:130-2. https://doi.org/10.1159/000507376.

Yang Y, Zhou Y, Liu X, Tan J. Health services provision of 48 public tertiary dental hospitals during the COVID-19 epidemic in China. Clin Oral Investig. 2020;24:1861-4. https://doi.org/10.1007/ s00784-020-03267-8.

Young JD, Abdel-Massih R, Herchline T, Mccurdy L, Moyer KJ, Scott $\mathrm{JD}$, et al. Infectious Diseases Society of America position statement on telehealth and telemedicine as applied to the practice of infectious diseases, Clin Infect Dis IDSA Telehealth Position Statement • CID. 2019;2019:1437. https://doi.org/10.1093/cid/ciy907.

Zhou X, Snoswell CL, Harding LE, Bambling M, Edirippulige S, Bai X, et al. The role of telehealth in reducing the mental health burden from COVID-19. Telemed e-Health. 2020;26:377-9. https://doi. org/10.1089/tmj.2020.0068.

Publisher's note Springer Nature remains neutral with regard to jurisdictional claims in published maps and institutional affiliations. 